\title{
Educación Artística y experiencia importada: Cuando la construcción de significados recae en lo anecdótico
}

\section{Artistic Education and Imported Experience: When the Creation of Meanings Relies in the Anecdotical}

\author{
Luisa María Gómez del Águila \\ Didáctica de la Expresión Musical, Plástica y Corporal. Universidad de Málaga. \\ lmdelaguila@uma.es \\ Carmen Vaquero-Cañestro \\ Didáctica de la Expresión Musical, Plástica y Corporal. Universidad de Málaga. \\ cvaquero@uma.es
}

Recibido: 14 de junio de 2013

Aprobado: 14 de octubre de 2013

\section{Resumen}

Vanguardia, innovación, expresión, libertad y creatividad son términos que espectadoras y espectadores asocian al arte. Sin embargo, son frustración, indiferencia, frivolidad, chorrada e incomprensión las sensaciones que manifiestan ante la obra actual, evidenciando una clara contradicción entre expectativas y realidad.

Paradójicamente, esta situación se perpetúa a través de vías que deberían propiciar el encuentro y que, por el contrario, están favoreciendo la consolidación de una imagen inmóvil y estereotipada del arte, que condiciona su propia conceptualización y, en consecuencia, también su vivencia. Surge así un sucedáneo del mismo a la vez encumbrado y denostado, relegado a espacios que nada tienen que ver con él ni con su valor y que, sin embargo, usurpa su lugar.

Este artículo, basado en la experiencia de múltiples encuentros mediados, evidencia las razones que lo sostienen en ese limbo inaccesible y, partiendo de la revisión conceptual, propone unos principios de acción para la generación de verdaderos espacios de encuentro entre obra y público. De auténticos espacios para el arte.

Originar estos espacios es la acuciante responsabilidad de la Educación Artística.

Palabras clave: educación artística, arte, público, tradición, experiencia artística.

Gómez del Águila, L.M., Vaquero-Cañestro, C. (2014): Educación Artística y experiencia importada: Cuando la construcción de significados recae en lo anecdótico. Arte, Individuo y Sociedad, 26(3) $387-400$

\begin{abstract}
Vanguard, innovation, expression, freedom and creativity are terms that viewers associate with Art. Nevertheless it is frustration, indifference, triviality, flapdoodle and lack of understanding the sensations they exhibit in front of the actual piece of art, showing a clear inconsistency between their expectations and reality.

Paradoxically, this situation is further more perpetuated by routines that should enable an approach but that, however, are promoting the consolidation of an immobile image and a stereotyped representation of art that affects its own conceptualization and, therefore, the art experience per se. This is how a surrogate of art emerges, sublimed and reviled at the same time, relegated to spaces that have nothing to do with Art itself or its value but that, all the same, takes its place.
\end{abstract}


This article, based on the experiment of multiple mediated encounters with art, proves the reasons that maintain Art in that inaccessible limb; and, starting from reviewing the concept, it also suggests certain action values to generate proper spaces where public and art work can convene; a creation of an authentic space for Art.

Creating these spaces is the imperative task of Artistic Education.

Keywords: arts education, arts, viewer, tradition, artistic experience.

Gómez del Águila, L.M., Vaquero-Cañestro, C. (2014): Artistic Education and Imported Experience: When the Creation of Meanings Relies in the Anecdotical. Arte, Individuo y Sociedad, 26(3) 387-400

Sumario: 1. Introducción. Un cúmulo de suposiciones que se dan por ciertas, 2. Lugares ajenos al arte: el reinado de lo anecdótico, 3 . El arte y sus representaciones: imágenes y discursos paralelos, 3.1. El Estado de la Inconsciencia, 4. Un falso salvoconducto: la aparente solidez de viejos conocimientos, 5. La deconstrucción del bagaje: responsabilidad y educación artística, 5.1. lo material no es el arte, 5.2. principios para el acercamiento, 5.2.1. los discursos paralelos, 5.2.2. escenarios para la autonomía, 5.2.3. la obra, 6. Aceptar el abismo: la oportunidad del arte. Referencias.

"El intento de revivir principios artísticos pasados puede producir, a lo sumo, obras de arte que son como un niño muerto antes de nacer" (Kandinsky, 1996, p. 21).

\section{Introducción. Un cúmulo de suposiciones que se dan por ciertas}

El ser humano, como ser indefectiblemente cultural, sólo se constituye como tal a través de un verdadero encuentro con la cultura (Morin, 2004; Vygotski, 1979). Por tanto, pensar en él, sin pensar en la cultura que lo conforma, tiene poco sentido. Por otro lado, la obra de arte, ente cultural autónomo, únicamente puede configurarse como tal en su auténtico encuentro con la persona. Solo así puede legitimarse. En otras palabras: sin esa confluencia, el arte, que "no es un conjunto de objetos bellos, sino el proceso mediante el cual articulamos una experiencia interior, con nuestras respuestas al mundo exterior" (Hernández, 2003, p. 118), no puede existir. Y a la vez, en su descubrimiento, nuestra especie se sublima: las obras "nos incitan a salir de nuestras preocupaciones humanas (...) y durante algunos segundos nos mantienen en suspenso en una existencia atemporal. Estos momentos excepcionales están más allá de la realidad diaria, son supersociales y, en cierto sentido, superhumanos" (Read, 2011, p. 85).

A pesar de ello, aunque el arte parece estar más al alcance que nunca de la sociedad que lo sustenta, la verdadera aproximación raras veces se produce (Agirre, 2005): la relación se establece sobre un cúmulo de suposiciones que se dan por ciertas, a pesar de estar basadas en discursos ahistóricos, conformados por datos aleatorios, anecdóticos y, en su mayoría, obsoletos (Vaquero, 2011). Esta situación se perpetúa a través de múltiples medios -libros, prensa, televisión, internet, museos, guías, docentes...- que deberían conformarse, en el sentido más vigotskiano de la palabra, como auténticos mediadores culturales (Vygotski, 1979).

Por el contrario, precisamente la naturaleza de su discurso, en un mundo cambiante y extremadamente complejo, impide indefectiblemente la experiencia artística, reduciéndola a un saber "importado", a un conocimiento adquirido de forma involuntaria e inconsciente, fruto de metanarrativas que se asumen sin haber cuestionado (Acaso, 2009). Siguen prevaleciendo sistemas de acercamiento a la obra 
que no propician la generación de experiencias propias y, por tanto, de verdaderas experiencias artísticas. De esta forma, el público no consigue traspasar el muro, figurado pero denso, que le separa del arte.

\section{Lugares ajenos al arte: el reinado de lo anecdótico}

La situación debería ser especialmente favorable en un momento en el que se han generado nuevos espacios para un arte que parece haberse desprendido del halo de genialidad que lo revistió durante siglos (Brea, 1991), y cuyo "consumo" ocupa una parte cada vez mayor de nuestro tiempo de ocio: el número de visitantes a museos y colecciones museográficas de arte contemporáneo de nuestro país ha pasado de 4.459.192 en 2000, a 12.023.260 en 2010 (INE y Ministerio de Educación, 2000, 2010).

Sin embargo, hay otra realidad: espectadoras y espectadores recorren museos y galerías de arte "con la mirada apagada: se han perdido entre personas que no hablan su lengua, con las que no pueden comunicarse de ninguna manera" (Read, 2011, p. 74). El tiempo dedicado a cada obra se reduce al mínimo (Almazán, 2008). La tendencia consumista, el carácter lúdico e incluso la espectacularización (Debord, 1999; Subirats, 1988), se erigen en marcadores que guían el itinerario experiencial de gran parte del público actual.

Estos factores y otros, también ajenos al arte, abortan la naturaleza artística de los nuevos artefactos: ya no es la obra quien media entre artista y sociedad. Así, se niega la posibilidad de una experiencia que permita, a cada persona, construir un imaginario propio, ajustado a su realidad y basado en la convergencia de los elementos que conforman su propia existencia, su propia cultura, anulando un proceso con un valor fundamental en la construcción del individuo (Agirre, 2005; Marín, 2003) Sin embargo, indiferentes a él, espectadoras y espectadores ni siquiera intuyen su potencial.

De este modo, en torno al arte de las últimas décadas, se ha generado un estable y casi generalizado Estado de la Inconsciencia, un territorio aparentemente seguro, firme, donde no existe conciencia de profundidad ni lugar para la duda. Donde la complejidad en forma de incertidumbre provoca magníficas resistencias (Morin, 2004) y los discursos, que aluden a la obra de arte e, incluso, a la propia idea de arte, versan sobre aspectos alejados de la misma, sin relación con su esencia ni con sus manifestaciones reales. Aquí, los esquemas conceptuales no se construyen a partir de obras, sino sobre representaciones de las mismas, cosas que parecen obras de arte pero no lo son, y discursos paralelos o ajenos a él que ocupan su lugar. De esta manera, no es posible el disfrute de la obra en cuanto Obra de Arte, y sus sucedáneos impiden el acercamiento íntimo y revelador que implica la experiencia artística (Brea, 1996).

\section{El arte y sus representaciones: imágenes y discursos paralelos}

Uno de los factores que propician esta realidad es, sin duda, la profusión de mensajes icónicos que caracteriza a nuestra sociedad (Hernández, 2007). Las imágenes protagonizan la configuración de un nuevo contexto cultural, ampliando las posibilidades comunicativas y ocupando espacios antes restringidos a los mensajes 
verbales (Acaso, 2007). Sin embargo, esta situación, en lugar de favorecer la adquisición de la autonomía necesaria para un acercamiento crítico a las imágenes -fundamentado en la mirada personal-, está obstaculizándola, al generar una importante sobrecarga visual que dificulta la discriminación.

En este contexto, las representaciones han adquirido un valor fundamental -al permitir una aproximación amplia, aunque superficial, a la obra de arte- pero ambivalente: incontables reproducciones, multiplicadas en infinitos espejos, brindan un encuentro perceptual con un reflejo de la obra que, a pesar de ser poco fidedigno, acerca al ser humano a creaciones a las que no podría acceder de otra manera (Freedman, 2006; Galí, 1988).

Las reproducciones mantienen, aunque de forma distorsionada, relaciones formales $-\mathrm{y}$, a veces, cromáticas- con el original. Sin embargo, han perdido su consistencia y su coherencia: son versiones minimizadas de la verdadera obra (Benjamin, 1973) que sustentan -e incluso configuran- los esquemas cognitivos de gran parte del público, generando un imaginario colectivo que, a su vez, condiciona la construcción del imaginario individual. Jean Baudrillard (1984), en un análisis de esta transfiguración entre lo real y su simulación, sostiene que "no se trata ya de imitación ni de reiteración, incluso ni de parodia, sino de una suplantación de lo real por los signos de lo real" (p. 11).

Es decir, como eco sostenido de la obra, sus réplicas asumen un papel de mediación quizá indispensable en otras facetas del conocimiento, pero fuera de lugar en una experiencia que es, por definición, directa e íntima. La trascendencia de esto solo puede entenderse si somos conscientes de que las reproducciones, en ningún caso, pueden adquirir la dimensión epistemológica de obra de arte, son otra cosa: "en el reino del simulacro la condición ontológica del ser de una cosa es su transformación en imagen" (Subirats, 1988, p. 106). En consecuencia, el acercamiento a ellas no puede considerarse una experiencia artística: es, también, otra cosa.

Pero esto no es lo peor. Entre arte y público median otras representaciones: profesionales e instituciones de toda índole, con una gran responsabilidad política y educativa, que deben ser conscientes del valor del arte en una sociedad necesitada de argumentos para la coherencia, siguen aferrándose a un uso frívolo e indiscriminado, elitista, reiterativo e inconsistente del mismo. Ejemplo paradigmático de ello es el uso promocional -y vacío de contenido- que ciudades y naciones hacen de artistas que han sido esenciales para la evolución del arte o, invirtiendo el fenómeno, la frecuente promoción -política y educativa- de personas cuya obra reitera momentos superados del arte y que, por tanto, no pueden considerarse más que pequeñas glorias locales. Del mismo modo:

Los objetos artísticos se transforman a través de la educación y a menudo pierden su identidad cultural. A medida que el currículum se va centrando en objetivos que son fácilmente enseñados y evaluados, los docentes utilizan con más frecuencia ejemplos típicos, que son fácilmente accesibles a través de publicaciones. Luego los estudiantes en prácticas utilizan los mismos ejemplos en su propia enseñanza y, en el proceso, los artefactos se simplifican y se segmentan. (Freedman, 2006, p. 44)

Así, a través de catálogos, paneles, publicidad, documentales, visitas guiadas, clases..., basados en asuntos anecdóticos que raramente apuntan al epicentro de la 
obra, se desvía la atención de espectadoras y espectadores de la cuestión esencial, resolviendo la tensión entre los "espacios de la presencia y tiempos de la experiencia" a los que alude Bayón (2012, p. 411) a través de esquemas cognitivos de acercamiento, construidos a partir de cuestiones accesorias que, en ningún caso, definen al arte. Esto genera lo que podemos llamar una experiencia importada o no-experiencia.

\subsection{El Estado de la Inconsciencia}

Esta experiencia importada se basa tanto en datos, quizá necesarios en otras disciplinas: Historia, Historia del Arte, Psicología..., como en la pura anécdota. En cualquier caso, del mismo modo que la sobrecarga de imágenes supone una barrera cognitiva difícilmente superable por el ser humano (Gómez del Águila, 2003), la acumulación de datos que los mediadores ofrecen alrededor de la obra -muchos de carácter fútil-constituyen un entramado prácticamente infranqueable para espectadoras y espectadores que nunca se han sentido partícipes del arte. Reproducciones y otras formas de discursos paralelos, se presentan como facilitadores y, sin embargo, generan barreras que neutralizan la obra.

$\mathrm{Si}$ a la dificultad de recordar excesivos datos no significativos para la experiencia, se suma su carácter episódico -al no apoyarse en otros ya conocidos ni vincularse con las propias vivencias-, el andamiaje que nos permitiría pasar de lo que Vigotsky (1979) denomina zona de desarrollo actual -como espectadoras y espectadores- a nuestro nivel de desarrollo potencial -ya como público- desaparece, y los datos se convierten en impedimento. Profesionales e instituciones contribuyen a la transmisión sistemática de valores que no son arte (historias, mitos, élites, transacciones, accidentes, apariencias...) y que, en consecuencia, no pueden conducir a la experiencia artística. De este modo, quienes pretenden aproximarse a ella, quienes desean formar parte de esa "expresión de la vida de la comunidad" (Dewey, cit. en Freeland, 2004, p. 78) que denominamos arte, limitados y sometidos a la interpretación, se sumergen en un proceso unidireccional básicamente guiado por lo narrativo. En otras palabras: los esquemas cognitivos con los que se acercan al arte se construyen a partir de cuestiones accesorias que, en ningún caso, lo definen.

Aspectos como las circunstancias en que se creó la obra, la paleta cromática que utilizaba el artista, su biografía -con especial atención a posición social, incomprensión por parte de sus coétaneos (Efland, Freedman y Stuhr, 2003), musas y amantes, enfermedades (principalmente mentales) y suicidios, en el caso de hombres; su filiación, enfermedades (físicas y mentales) y accidentes, en el caso de mujeres-, el precio de la obra, las veces que ha sido robada o víctima del vandalismo y un sinfín de cuestiones superfluas que rodean la verdadera cuestión, desvían la mirada del único espacio en el que el encuentro con el arte es posible.

Pero la acumulación de datos no solo distrae la atención del foco: su abuso fomenta la dependencia, y esto no ocurre con otro tipo de manifestaciones artísticas. ¿Nos imaginamos que fuera habitual que antes de ir al cine alguien nos explicase en detalle la película o, lo que es peor, lo hiciera durante su proyección? Este apoyo sistemático en elementos externos terminaría interiorizándose, generando una dependencia que no permite el acercamiento íntimo y personal a la obra necesario para la experiencia 
artística (Eco, 2002), y que desemboca en la desconfianza del público en sus propias posibilidades. A esto se suma la frecuente fragmentación de la obra en elementos que jamás tienen entidad por sí mismos, con la excusa de alfabetizar a un público que, así tratado, no puede dejar de sentirse analfabeto.

La cuestión se complica aún más por la repetición sistemática de una selección muy limitada de obras que en algún momento se consideraron representativas de determinados períodos y territorios (Hernández, 2007), y que, convertidas en icono más allá de los mismos, pugnan por perpetuar su legitimación como paradigma único, dando a entender que el buen arte ya está hecho, y que el actual jamás podrá alcanzar las cotas de maestría de su predecesor. La insistencia en representaciones propias de periodos artísticos pasados, genera una noción -formal y conceptual- en la que el peso de la tradición excede lo razonable, más aún en una sociedad en la que constantemente se amplían los cauces de la expresión artística: "además, la perfección misma de esos productos, el prestigio que poseen a causa de una larga historia de indiscutible admiración, crean convenciones que obstruyen una visión fresca" (Dewey, 2008, p. 3).

Así, a través de reproducciones y otras narrativas, la tradición, mediante esquemas caducos -no por su valor intrínseco, sino por su ineficacia para enfrentar las obras actuales-, se obstina en perpetuarse, invalidando, de forma implícita, el arte del momento. En tal situación, el público, que nada entre dos aguas -la seguridad de creer que aplica los parámetros clásicos, al considerar, por ejemplo, que el parecido con la realidad observable formaba parte de ellos, y la inseguridad de no tener ningún otro parámetro conocido que aplicar- opta por la seguridad. Para Danto (1999), "el gran paradigma tradicional de las artes visuales ha sido, de hecho, el de la mímesis, que sirvió admirablemente a los propósitos teoréticos del arte durante varios siglos" (p. 51).

Espectadoras y espectadores "no reconoce(n) como suyo el arte de su época" (Guasch, 2000, p. 17): desconfían de urinarios, estructuras primarias, mierdas enlatadas, escaleras rojas, montones de pipas... o, lo que es lo mismo, de conceptos alternativos, como "configuración", "presentación", "cosificación” (Vaquero, 2011), aferrándose a un modelo narrativo ya superado, y cerrando los ojos ante sistemas más acordes a la realidad postmoderna. El público habita el Reino de lo Anecdótico, donde gobierna la tradición, presidida, a su vez, por el principio de representación más elemental.

En la maraña de verdades interpuestas que configuran este conocimiento importado, el pasado es el elemento fundamental, haciendo del universo del arte un habitáculo anquilosado y estanco. Mientras las obras más conocidas se muestran hasta la saciedad, la poca obra actual que llega a nuestra retina no encaja en los antiguos esquemas y, resultando poco significativa, se desecha pronto. Tanto es así, que en nuestra memoria, cargada de obra clásica, apenas hay referentes de lo sucedido en las últimas décadas. "Estamos atados de pies y manos al pasado" (Read, 2011, p. 77).

\section{Un falso salvoconducto: la aparente solidez de viejos conocimientos}

Esos discursos, erigidos en representación de la obra, se convierten en auténticas barreras cognitivas: en lugar de ejercer como verdaderos mediadores, anulan-bajo 
apariencia emancipadora- la posibilidad de que emerjan inquietudes con respecto a la obra en sí y, en consecuencia, con respecto a la propia idea de arte. Aferrado a ellos, el público no afronta el proceso de reorganización mental que exige el aprendizaje, y esquemas cognitivos ajenos a la experiencia personal $-\mathrm{y}$, por tanto, inválidossubsisten gracias a experiencias importadas.

Espectadoras y espectadores, a fuerza de recibir instrucciones sobre la lectura de la obra -no solo acerca de cómo interpretarla: también sobre qué sentir ante ella-, son situados por debajo de la misma, limitando su participación al estatismo de la mera interpretación consentida por la obra tradicional, en la que la pintura se yergue como paradigma del arte (Danto, 1999). El público, convertido así en objeto, cuya función principal es descifrar lo que cada artista pretendió decir, permanece ajeno a la necesidad de construir esquemas personales en los que basar su mirada y sigue transitando lugares donde no hay obras de arte, porque solo llegan sus reflejos.

La tradición y los conocimientos especializados siguen pareciendo el salvoconducto para atravesar la pared, como si las representaciones -imágenes y discursos paralelosque, en gran medida, fundamentan nuestra experiencia del arte, pudieran llevarnos a él. Pero, ¿y si la aparente solidez de los argumentos conocidos estuviese impidiendo el acercamiento capaz de hacer que el muro se desvanezca? ¿Y si fuera necesario "navegar en un océano de incertidumbres a través de archipiélagos de certeza" (Morin, 2001, p. 21)? ¿Y si la llave no fuese el conocimiento, sino la predisposición desde la inocencia?

Nuestra sociedad, habituada al ritmo de un consumo fácil y desenfrenado, siempre tiene prisa. El arte se ha convertido en producto prestigioso pero fácilmente digerible para el tiempo de ocio (Marchán, 2001) y, como todo lo demás, se espectaculariza: no importa si quienes asisten a una exposición realmente llegan a establecer conexiones con la obra, sino lo largas que fueron las colas o el número de visitas registradas en la web del museo. Ni público ni obra cuentan. Solo los beneficios que ese encuentro de cara a la galería, efímero e interesado, puedan generar.

De este modo, una y otro son instrumentalizados en sentidos opuestos: mientras la obra, convertida en foco del espectáculo mediático, alcanza un ritmo vertiginoso, símbolo del dinamismo de la sociedad actual, el público, estático, permanece, como si una pared de cristal le separase de la obra, impidiéndole seguir una evolución a la que se siente ajeno. Es difícil que encuentre acomodo entre las innumerables propuestas que demandan su atención. La brecha parece insalvable.

\section{La deconstrucción del bagaje: responsabilidad y Educación Artística}

Sabemos que la acumulación de fenómenos, hechos y datos, no provoca aprendizaje: este solo se produce cuando ese conjunto de experiencias ocasiona una reorganización mental; sabemos que al arte no se llega a través de reseñas, sino mediante posibilidades reales de vivir experiencias artísticas (Brea, 1991); y sabemos también que lo que espectadoras y espectadores siguen recibiendo es, básicamente, una gran cantidad de información sobre aspectos tangenciales que monopolizan el espacio de encuentro, impidiendo la generación de esquemas mentales propios con los que acercarse a la obra del siglo XXI.

Esta realidad trasciende lo que suele considerarse como mero "goce estético": si el 
desarrollo de una persona no puede entenderse fuera de la cultura a la que pertenece, y si el arte es "la más grande conquista intelectual en la historia de la humanidad" (Dewey, 2008, p. 29), la situación que describimos afecta tanto a dicha construcción personal, como al avance cultural de una sociedad que pretende legitimarse como Sociedad del Conocimiento. Así, podemos:

a) Aceptar que la brecha es insalvable. Es decir, que el arte, por su propia naturaleza, pertenece a la élite o avanzadilla de cada sociedad: quienes crean son seres elegidos que guían al pueblo con mensajes difícilmente descifrables por su carácter avanzado o su valor transgresor.

b) Considerar que la brecha no es más que un desencuentro, fruto de intervenciones basadas en un paradigma -transmisión de datos = experiencia artística- que podemos superar. Es decir, creer en la posibilidad de deconstruir este sistema de acercamiento a la obra que, a fuerza de repetirse, ha llegado a ocupar el espacio necesario para la experiencia artística.

Aceptar la primera opción supone proclamar la muerte de un arte que depende de la participación consentida y activa del público (Chavarría, 2002; Fischer, 1999):

(...) el espectador no es el elemento pasivo del fenómeno, sino que el resultado de su acción pasa a formar parte integrante de la estructura compositiva de la obra. El espectador dinámico es al mismo tiempo receptor y creador a diferencia del receptor contemplativo de una pieza tradicional, que es un sistema cerrado a la producción. El arte participativo traslada responsabilidad creativa al espectador. (Aguilar, 2010, p. 25)

Si añadimos que la Cultura únicamente puede construirse desde la constante generación,

solo queda una salida: encontrar un modelo que permita afrontar el sinsentido de una concepción atávica y estanca, que tolera -y sigue consolidando- esta situación.

Si la cultura desde el poder no es verdadera Cultura (Read, 2011), es necesaria una profunda revisión que posibilite a cada componente de cada sociedad intervenir en la generación de auténtica Cultura, construyendo imaginarios personales y colectivos que, retroalimentándose, debiliten el protagonismo de estructuras de poder con intereses ajenos al arte. Aún siendo conscientes de la fuerza de estos poderes y de la dificultad de alterar un sistema encapsulado durante siglos, es imprescindible iniciar un cambio que permita modificar esquemas basados en una realidad que ya no existe y que se fundamenta en definiciones trasnochadas que aún se dan por válidas, tales como el uso institucionalizado de la expresión "Bellas Artes" o la definición de "artístico" vigente en la 22 a edición del diccionario de la Real Academia Española, y que apenas varía en el avance de la $23^{\mathrm{a}}$.

El arte pide una oportunidad.

\subsection{Lo material no es el Arte}

El arte pertenece al mundo de los significados: lo material no es el arte, el urinario no es el arte, las latas tampoco..., lo son sus relaciones con el universo de lo exclusivamente humano del que forman parte. Así, la obra actual se alza como una microrrealidad frente a la realidad dominante $\mathrm{y}$, mediante vías de acceso muy 
atractivas, aporta relaciones insospechadas con la materia, en las que confluyen nuevas percepciones sobre el mundo y sobre el propio arte.

La educación no puede perder de vista este punto de partida. Es necesario impulsar una nueva concepción de arte que favorezca la toma de conciencia, y superar la idea generalizada que lo reduce a materia de reproducción y esparcimiento (Gutiérrez, 2012). Para ello es imprescindible modificar todos aquellos contextos que, en mayor o menor medida, se vinculan a la Educación Artística, e inciden tanto en la construcción de los primeros esquemas mentales, como en la deconstrucción de los que dificultan la experiencia artística en momentos posteriores.

Si para el desarrollo cognitivo son fundamentales tanto la selección de contenidos culturales como la forma en que estos se abordan, es esencial una práctica coherente con la realidad actual, partiendo de la revisión de errores que giran, principalmente, en torno a los discursos sobre la obra, las relaciones con la tradición (Parramón, 2003) y la forma en que nos acercamos a ella.

En un mundo globalizado donde las tecnologías de la información y la comunicación son básicas para el acceso al conocimiento, las reproducciones forman parte del proceso de "culturización" que nos convierte en seres históricos. En este sentido su utilidad es evidente. Sin embargo, aun reconociendo su indiscutible valor como referentes culturales, debemos asimilar que, en ningún caso, pueden ocupar el lugar del arte. Porque solo en la conjunción insólita de elementos tangibles e intangibles -formato, materiales, dimensiones, composición...-, que convergen en un todo único y premeditado, se conforma esa apariencia intencionada (Ground, 2008) que sustenta la obra de arte. Alterar dicha apariencia es, sencillamente, hacer desaparecer la obra. Sea cual sea la vía de acercamiento al arte, nunca puede iniciarse a través de reproducciones.

Es responsabilidad de la Educación Artística terminar con la perversión que supone que los esquemas cognitivos con los que niñas, niños y mayores van a acercarse a la obra sigan construyéndose -o afianzándose- a partir de ellas. Inducir a la sociedad a esperar de una representación lo que solo puede ofrecer la obra, conduce a la frustración inmediata, a la falta de expectativas y al distanciamiento del arte. Por tanto, debemos ser conscientes de que la relación únicamente puede iniciarse en contacto directo con la obra: en centros de arte, a través de obra virtual, mediante producción propia no condicionada... Es decir, en lugares donde sus propiedades exclusivas no queden neutralizadas. En otras palabras: si queremos aprender a establecer relaciones con el arte, tenemos que situarnos en sitios donde haya arte. Los materiales para observar, colorear o re-reproducir: cuadernillos, libros de texto, aplicaciones informáticas... jamás pueden ser el eje sobre el que se construyan los esquemas de acercamiento.

A la vez que cuestionamos el uso de las reproducciones, es necesario cuestionar su contenido. Un rápido vistazo a espacios y medios educativos, evidencia la constante repetición de un número muy limitado de iconos procedentes del pasado. Es decir, el imaginario artístico colectivo sigue construyéndose a partir de obras archiconocidas que, en muy pocas ocasiones, se acercan al siglo XX. De este modo, el arte queda reducido a un antiguo estereotipo de sí mismo.

Así, espectadoras y espectadores de cualquier edad, se hacen una idea del arte alejada de su carácter universal que provoca el rastreo de la obra actual en busca de 
características episódicas, propias de diferentes momentos históricos pero que, en ningún caso, pueden generalizarse. En consecuencia, tampoco pueden ser la base de la experiencia artística. Menos aún si consideramos que esta jamás se fundamenta en la transmisión de imágenes, datos y anecdotarios, en una revisión inacabable de los mismos. "Nuestra aprehensión del valor de los fenómenos estéticos es lógicamente independiente de otras actividades. Así pues, las explicaciones de este valor en términos de algo más, no son relevantes" (Ground, 2008, p. 145). Garantizar un espacio en el que sea posible un encuentro entre público y obra, pasa por establecer una clara diferenciación entre Arte e Historia del Arte (Vaquero y Gómez, 2012). La mera revisión no es suficiente.

La Educación Artística debe responsabilizarse de esta situación e iniciar una deconstrucción de esquemas capaz de posibilitar el desarrollo de otros nuevos que, aun estableciendo con la tradición unos lazos razonables, sean radicalmente coherentes con la realidad actual. La sociedad no puede dirigir su mirada al pasado: el arte siempre mira al futuro y construyéndolo, construye el presente. Lo contrario supone negarle su valor esencial: la constante generación.

\subsection{Principios para el acercamiento}

Si la enseñanza que se dirige a una etapa anterior del desarrollo, es ineficaz (Vigotski, 1986), y si la obra solo puede entenderse como un ente en continua metamorfosis (Vaquero, 2011), la Educación Artística debe actuar en consecuencia y ayudar a la sociedad, a toda la sociedad, a encarar el tiempo del arte, su propio tiempo. Espectadoras y espectadores no pueden permanecer estables, ajenos a un ritmo vivo, absortos en momentos anteriores de la Historia (Gardner, 1996).

Desde la comprensión de la pereza que el actual relativismo -en apariencia, excesivo- puede dar a un público asentado en una seguridad renacentista, nuestra responsabilidad es frenar la inercia, destruir las inciertas seguridades de las que partimos y aniquilar el Estado de la Inconsciencia que hemos generado. Solo cuando la deconstrucción termine, podremos iniciar el constante proceso de actualización que supone el encuentro con la obra.

Sin embargo, la reflexión sin una acción compartida que facilite el encuentro, únicamente puede devenir en una entelequia válida para especialistas, pero inútil para un público ávido de vivencias. Necesitamos con urgencia principios de acción, que permitan frenar este distanciamiento. Este trabajo propone una articulación de dichos principios en torno a dos ámbitos que es preciso diferenciar: la obra y los discursos paralelos. Debemos cerrar la brecha.

\subsubsection{Los Discursos Paralelos}

Es responsabilidad de la Educación Artística modificar los esquemas de acercamiento vigentes en el Estado de la Inconsciencia. Es imprescindible asumir que:

- El arte es hijo de su tiempo. No anda hacia atrás ni puede repetirse. Perseguir en la obra el pasado en forma de realidad observable, genialidad, virtuosismo, fama, familiaridad... implica autoexcluirse. 
- Los discursos paralelos son, siempre, ajenos a la obra. No la explican ni la completan en cuanto posibilidad del arte. En este sentido, son pura anécdota. Debemos revisar minuciosamente la necesidad, el cuándo, el qué y el cómo de dichos discursos.

- La cultura genera desarrollo y, la subcultura, subdesarrollo. La información que se ofrece para ampliar conocimientos o satisfacer curiosidades, puede ampliar o reducir puntos de vista, y abocar -o no- al fracaso. Por ello, debemos tomar conciencia de nuestros criterios de selección, y evidenciarlos.

- A la vez, debemos asumir que proporcionar datos antes de que alguien haya podido establecer sus propios vínculos con la obra, es una forma de sesgar -y, en consecuencia, despersonalizar- su experiencia. Por tanto, cualquier acción en este sentido debe ser posterior al encuentro.

- Cuando, para ampliar horizontes, estos discursos incluyan reproducciones de obra, es imprescindible evidenciar la distancia que media entre una y otras. No podemos seguir alimentando una confusión que frustra cualquier posibilidad de arte.

\subsubsection{Escenarios para la Autonomía}

Es responsabilidad de la Educación Artística:

- Diseñar escenarios que permitan a espectadoras y espectadores de cualquier edad vivir el arte de la única forma posible: con autonomía. Hablamos de contextos horizontales que, lejos de la instrucción, sean capaces de albergar auténticas experiencias artísticas, esenciales para la configuración de nuestras identidades personales y colectivas.

- Liberar el encuentro de procesos informativos: igual que no se explica al público una película durante su proyección, no podemos ofrecer interpretaciones -ni siquiera heredadas del propio artista- cuando una persona se aproxima a la obra. Hacerlo implica negarle su propia vivencia.

- Abandonar cualquier práctica no emancipatoria, como guiar la mirada o describir la obra -o sus sucedáneos- cuando, lo que se persigue, es la vivencia: esta es personal e intransferible... o no es.

No podemos seguir infravalorando al público, del que formamos parte.

\subsubsection{La Obra}

Es responsabilidad de la Educación Artística:

- Partir, siempre, del encuentro con la obra -no con reproducciones- a través de centros de arte, videocreaciones, creación propia... porque solo desde aquí pueden generarse esquemas válidos para el acercamiento.

- Cargar el imaginario colectivo de obra actual, evitando la reiteración de obra pasada.

- Ofrecer propuestas que abarquen diversos lenguajes y culturas no hegemónicas, tanto en aspectos territoriales como ideológicos o de cualquier otra índole, puesto que estos son los referentes del arte del XXI. 


\section{Aceptar el Abismo: La Oportunidad del Arte}

Es responsabilidad de toda la sociedad un cambio de actitud, que implica:

- Aceptar que hoy, el arte, no es una entidad reverenciable, sino la oportunidad que nos damos artistas y público de construir el futuro en el encuentro con la obra. No existen plantillas de ayuda, porque el arte se genera en cada encuentro. Hay que quebrar las seguridades y controlar nuestra angustia. Debemos aceptar el abismo.

- Asumir que la vivencia del arte no es un pasatiempo. No es fugaz. No es comercial. Exige predisposición, un momento de intimidad, una atención diferente en la que el tiempo cuenta: requiere un instante lento, donde nada ajeno tenga cabida. Una oportunidad.

$\mathrm{Si}$, a través de todo ello, llegamos a entender que la piedra de toque es la diferencia entre "saber de arte" y "vivir el arte"; que la obra, sin público, no se completa... Que el objetivo no es conocer todo lo que se produce, en un mundo complejo, cambiante e inabarcable, sino poder disfrutar las obras que conocemos. Que espectadoras y espectadores no buscamos ser expertos: lo único que perseguimos -y, con toda legitimidad- es sabernos integrantes, sujetos, partícipes, cómplices, coautores del arte... Si, desde esta consciencia, modificamos nuestras propias estructuras quizá, por fin, la brecha desaparezca. Y la sociedad, toda la sociedad, pueda saberse protagonista del arte.

\section{Referencias}

Acaso, M. (2007). Esto no son las Torres Gemelas. Cómo aprender a leer la televisión y otras imágenes. Madrid: Los libros de la Catarata.

Acaso, M. (2009). La educación artística no son manualidades. Nuevas prácticas en la enseñanza de las artes y la cultura visual. Madrid: Los libros de la Catarata.

Agirre, I. (2005). Teorías y Prácticas en Educación Artística. Barcelona: Ediciones OCTAEDRO/EUB-Universidad Pública de Navarra.

Almazán, L. (2008). Museos y Público. Análisis de un estudio en el centro José Guerrero de Granada. MUS-A. Revista de los museos de Andalucía, VI (10), 72-79.

Aguilar, G. (2010). La interacción, la interpretación y la implicación como estrategias participativas. Time Divisa de Antonio Vega Macotela. Arte y políticas de identidad [en línea], vol. 3 (diciembre), 9-28. Recuperado dehttp://revistas.um.es/ api/article/view/117381/111031

Bayón, F. (2012). Las retóricas del público. El espacio de consumo del arte como institución política. Arbor Ciencia, Pensamiento y Cultura, 188-754, 409-426.

Baudrillard, J. (1984). Cultura y Simulacro. Barcelona. Editorial Kairós.

Benjamin, W. (1973). La obra de arte en la era de su reproductibilidad técnica. Recuperado dehttp://www.jacquesderrida.com.ar/restos/benjamin_arte.htm

Brea, J. L. (1991). Las auras frías. Barcelona: Editorial Anagrama.

Brea, J. L. (1996). Un ruido secreto. El arte en la era póstuma de la cultura. Barcelona: Editorial Anagrama.

Chavarría, J. (2002). Artistas de lo Inmaterial. Hondarribia (Guipúzcoa): Nerea. 
Danto, A. (1999). Después del fin del arte. El arte contemporáneo y el linde de la historia. Barcelona: Paidós.

Debord, G. (1999). La sociedad del espectáculo. Madrid: Pre-textos.

Dewey, J. (2008). El arte como experiencia. Barcelona: Paidós Ibérica.

Freedman, K. (2006). Enseñar la cultura visual. Barcelona: Ediciones Octaedro.

Eco, U. (2002). La definición del arte. Barcelona: Ediciones Destino.

Efland, A., Freedman, K., y Stuhr, P. (2003). La educación en el arte posmoderno. Barcelona: Paidós Ibérica.

Fischer, E. (1999). La necesidad del arte. Madrid: Ediciones Altaya.

Freeland, C. (2004). ¿Pero esto es arte? Madrid: Cátedra.

Gardner, J. (1996). ¿Cultura o basura? Madrid: Acento Editorial.

Galí, M. (1988). El arte en la era de los medios de comunicación. Madrid: Los Libros de Fundesco.

Gómez del Águila, L. M. (2003). La Alhambra a Ciegas: Propuesta de un método de comunicación del entorno abierto a personas con ceguera o baja visión. Universidad de Granada. (Tesis inédita de doctorado).

Guasch, A. M. (2000). El arte último del siglo XX. Del posminimalismo a lo multicultural. Madrid: Alianza.

Ground, I. (2008). Arte o chorrada. Valencia: Universidad de Valencia.

Gutiérrez, R. (2012). Reflexiones en torno a la planificación y el desarrollo del currículum artístico. Ponencia presentada al IV Congreso Internacional de Educación Artística y Visual. Aportaciones desde la periferia. Jaén, 19-21 de abril. Hernández, F. (2003). Educación y Cultura Visual. Barcelona: Ediciones Octaedro.

Hernández, F. (2007). Espigador@s de la cultura visual. Barcelona: Ediciones Octaedro.

Kandinsky, W. (1996). De lo espiritual en el arte. Barcelona: Paidós.

Marchán, S. (2001). Del arte objetual al arte de concepto. Madrid: Ediciones Akal.

Marín, R. (2003). Aprender a dibujar para aprender a vivir. En R. Marín (Ed.) Didáctica de la Educación Artística (3-51). Madrid: Pearson Education.

Ministerio de Educación, Cultura y Deporte (2000). Estadísticas de museos y colecciones museográficas 2000. Recuperado de Recuperado de http://www.mcu. es/estadisticas/MC/EM/2000/DescargaDatos.html

Ministerio de Educación, Cultura y Deporte (2010). Estadísticas de museos y colecciones museográficas 2010. Recuperado dehttp://www.calameo.com/ $\mathrm{read} / 000075335 \mathrm{e} 7 \mathrm{de} 6 \mathrm{~d} 0 \mathrm{~d} 71 \mathrm{~b} 2$

Morin, E. (2001). Los siete saberes necesarios para la educación del futuro. Barcelona: Paidós.

Morin, E. (2004). La epistemología de la complejidad. Gazeta de Antropología, 20, artículo 02. Recuperado de http://digibug.ugr.es/handle/10481/7253 DOI http:// hdl.handle.net/10481/7253

Parramon, R. (2003). Arte, Participación y Espacio público. Ponencia presentada en la Jornada d'Innovació Estratègica: Models de Participaciò en Xarxa, UPC: Barcelona, España.

Read, H. (2011). Al infierno con la cultura y otros ensayos de estética. Madrid: Cátedra. 
Subirats, E. (1988). La cultura como espectáculo. Madrid: Fondo de Cultura Económica.

Subirats, E. (1989). El final de las vanguardias. Barcelona: Editorial Anthropos.

Vaquero, C. (2011). De los Regionalismos a la Globalización. El proceso de Homogeneización del arte. Los traslados focales del arte: desde la visión contextualizada del objeto artístico a su progresiva desmaterialización en el siglo $X X$. (Tesis inédita de doctorado). Universidad de Sevilla.

Vaquero, C., y Gómez del Águila, L. M. (2012). Obra y público, tradición y generación: ¿Cómo propiciar el encuentro? Dedica. Revista de Educação e Humanidades, 3, 197-204.

Vygotski, L. S. (1979). El desarrollo de los procesos psicológicos superiores. Barcelona: Crítica. 